\title{
Experimental Physeal Distraction in Immature Sheep
}

\author{
J. De Pablos, Jr., M.D., and J. Cañadell, M.D.
}

From the Department of Orthopaedics, University Clinic of Navarra, Pamplona, Spain.

Reprint requests to J. de Pablos, Jr., M.D.

Department of Orthopaedics, University Clinic of Navarra.

Aptdo. 192, 31080 Pamplona, Spain.

\begin{abstract}
An experimental study on physeal distraction was carried out in the distal femur of 45 two-month-old lambs for the purpose of identifying the basic mechanism of lengthening as well as assessing growth cartilage viability after lengthening. The animals were divided into three groups, each with three subgroups, according to the distraction rate employed ( $2 \mathrm{~mm} /$ day, $1 \mathrm{~mm} /$ day, $0.5 \mathrm{~mm} /$ day) and the time at which the animals were killed (end of lengthening, 1.5 months postlengthening, and at six months of age). Another group of three animals whose femurs were lengthened at a rate of $0.5 \mathrm{~mm} /$ day was killed ten days postoperatively. Roentgenologic, specimen measurements, and histologic studies were performed on all animals. The results obtained showed that the basic mechanism for lengthening is the production of a physeal fracture between degenerative and calcified layers; this finding was consistent. It was also observed that the lower the rate of distraction employed, the greater was the short- and long-term viability of the growth cartilage. More specifically, optimal viability was observed when a distraction rate of $0.5 \mathrm{~mm} /$ day was employed.
\end{abstract}

\section{INTRODUCTION}

Physeal distraction as a method for leg lengthening was reported for the first time by Ring $^{26}$ in 1958. Zavijalov and Plaskin ${ }^{31}$ in Eastern Europe published the first report, to the present authors' knowledge, on the clinical application of this lengthening technique in 1967. Physeal distraction has some advantages over other lengthening methods. It is a less invasive procedure and insures consolidation. However, problems remain to be resolved. Two of the most important questions concern the mechanism by which lengthening is produced and the viability and function of the growth cartilage after distraction.

The present study was undertaken with the following objectives in mind: (1) to study the basic mechanism through which physeal lengthening is brought about and (2) to study the viability of the growth cartilage after physeal distraction and the factors that affect it. 


\section{MATERIALS AND METHODS}

Lambs were used because of their docility and size, and the availability of the gender, weight, and age desired. A total of 45 two-month-old Merino lambs weighing between 13 and $15 \mathrm{~kg}$ were used, of which 40 were male, and five were female. Skeletal maturity in this breed is reached at approximately eight months of age.

The distraction device employed was an experimental prototype of the dynamic axial fixator (Orthofix, Verona, Italy) ${ }^{3}$ with self-tapping tapered threaded pins of 3.5- to 4.5$\mathrm{mm}$ intraosseous diameter and an extraosseous diameter of $6 \mathrm{~mm}$. Placement of the device was performed with the animal under general anesthesia, in aseptic conditions, and under roentgenographic control. Distraction was begun 36 hours after surgical intervention and continued until $2 \mathrm{~cm}$ of lengthening was obtained in all animals.

The 45 sheep were divided into three groups of 15 each based on the distraction rate employed: Group A had a distraction rate of $2 \mathrm{~mm} /$ day; Group B, $1 \mathrm{~mm} /$ day; Group C, $0.5 \mathrm{~mm} /$ day. Therefore, $2 \mathrm{~cm}$ of distraction was achieved in ten days in Group A, in 20 days in Group B, and in 40 days in Group C. Each group was further divided into three subgroups according to when the animal was killed. In Subgroup 1, animals were killed at the completion of lengthening; in Subgroup 2 at 1.5 months postlengthening, and in Subgroup 3, at six months of age, that is, four months after the distraction was begun.

Evaluation of the results comprised the following: (1) roentgenologic study of the lengthened femur by anteroposterior (AP) view immediately postoperatively and by AP and lateral views of both femora immediately after death; (2) specimen measurements of both femora and tibiae of all lambs immediately postoperatively and in intermediate stages (at the end of lengthening, 45 days after the end of lengthening, and at six months of age), according to the lifespan scheduled for each Iamb; and (3) histologic study at the level of the distal extremity of both femora (control and lengthened) of each animal using hematoxylin-eosin and Masson's trichromic stains.

Besides the 45 animals mentioned, three lambs were added to the experiment (Group D). In this group, physeal distraction was carried out at a rate of $0.5 \mathrm{~mm} /$ day, but the animals were killed after ten days of distraction. Roentgenograms were taken in the immediate postoperative and post-modem periods. Postmortem histologic studies were performed as they were in the other 45 animals of the experiment. The objective of including this group in the experiment was to observe changes produced by a very slow physeal distraction after a very short postoperative period.

\section{RESULTS}

\section{Roentgenologic study}

Regardless of the distraction rate employed, very similar roentgenographic images were seen in all cases at each stage of the experiment. Consistently, just after lengthening was begun, a radiotransparent gap between the metaphysis and epiphysis was observed (Figs. $1 \mathrm{~A}$ and 1B). Consolidation of the lengthened segment was found to be well advanced 1.5 months postlengthening (Fig. 1C), and at six months of age, i.e., four months postoperatively, this reconstruction was virtually complete in all cases regardless of the rate of distraction (Fig. 1D). 
Although differences were minimal, it should be noted that a finer trabeculation could be detected in the lengthened segments of femora distracted at $0.5 \mathrm{~mm} /$ day (Subgroup C3). This suggests better consolidation of the lengthened segments in these animals.

In all lengthened femora in Group D, a roentgenologic image was observed similar to the one observed in the other lengthened femora studied just at the end of distraction (Subgroups A 1, B1, and Cl) with a shorter lengthened segment.

\section{Specimen measurements}

Although all femoral and tibial specimens were measured, only the results of the discrepancies between lengthened and contralateral limbs in the animals followed the longest, i.e., those that were killed at six months of age, will be presented. Figure 2 illustrates that, after the distraction was completed, almost parallel decreases in the amount of discrepancy were observed initially in all three subgroups. This is because, during that time (1.5 months), the distractor was used in such a way as to avoid collapse of the lengthened segment. Later, in the free-growth stage, the discrepancy between the operated and unoperated sides was well maintained in the subgroup that had distraction at a rate of $0.5 \mathrm{~mm} /$ day, while in the other subgroups (especially in Subgroup A3) a progressive decrease in the amount of discrepancy was observed. Thus, the discrepancy was better maintained in, those femora in which lengthening had occurred at slower speeds.

\section{Histologic study}

Histologic study concentrated on three points: (1) the immediate morphologic changes, (2) the subsequent physeal morphologic changes, and (3) the morphology of the lengthened segment.

Immediately after distraction was concluded, the presence of a fracture between the metaphysis and the epiphysis with an interspace (lengthening focus) in a fairly advanced state of reconstruction was confirmed (Fig. 3A). In Subgroup A 1 specimens, since only ten days had elapsed since the distraction was begun, the fracture line was quite easily observable: distally (Fig. 3B) it corresponded to the hypertrophic layer of growth cartilage, and proximally (Fig. 3C) it corresponded to the calcified stratum that remained attached to the distal femoral metaphysis. In Subgroups B1 and C1, i.e., limbs lengthened at slower rates $(1 \mathrm{~mm} /$ day or $0.5 \mathrm{~mm} /$ day $)$, the reparative process was more advanced and the fracture lines were not quite as clear (Fig. 3D).

The histologic study of the lengthened femora of Group D $(0.5 \mathrm{~mm} /$ day of distraction studied ten days postoperatively) helped clarify this last point. In all three cases in Group D, a very clear physeal fracture similar to the physeal fractures seen in Subgroup A1 was observed. As in Subgroup A1, the lengthening focus was occupied by a hematoma in all three cases (Fig. 4).

With reference to the physeal morphologic changes, it was found that greater rates of distraction led to more pathologic changes in the growth cartilage.

Distraction Rate of $2 \mathrm{~mm} /$ day (Group A). In animals whose limbs were lengthened at a rate of $2 \mathrm{~mm}$ /day and that were killed immediately after lengthening (Subgroup A1), a thinning of the germinal layer and thickening of the proliferative and hypertrophic 
layers were observed, such that the cartilage on the lengthened side was thicker than on the control side. Longitudinal gaps in the distracted growth cartilage were likewise frequently observed.

In Group A animals killed 15 months after lengthening (Subgroup A2), considerable destruction of the cartilaginous layers on the lengthened side as well as extensive thinning of the germinal layer were observed. Two cases in this subgroup had complete destruction of the growth cartilage along with degeneration of the germinal layer and calcification of the rest of the physis.

Finally, in Group A animals killed at six months of age (Subgroup A3), the cartilage of the lengthened side demonstrated an almost complete disappearance of the germinal layer, while the remainder of the cartilage consisted of hypertrophic and degenerative cells (Figs. 5A and 5B). Physeal bone bridges were also frequently observed on the lengthened side.

Distraction Rate of $1 \mathrm{~mm} /$ day (Group B). Group B animals killed just after lengthening (Subgroup $\mathrm{Bl}$ ) demonstrated thinning of the germinal layer, while the remaining growth cartilage on the lengthened side continued to be just slightly abnormal. Those killed 1.5 months after lengthening (Subgroup B2) showed progressive destruction of the growth cartilage on the lengthened side, while the germinal layer continued to thin out. At six months of age (Subgroup B3; Figs. 5C and 5D), the growth cartilage on the lengthened side still had a thinned germinal layer, while the remainder appeared to be morphologically more active than in the same subgroup lengthened at $2 \mathrm{~mm} /$ day (Subgroup A3).

Distraction Rate of $0.5 \mathrm{~mm} /$ day (Group C). In Group C animals, only minimal differences were observed between the control cartilage and that of the lengthened side. This was true in all three subgroups, especially in Subgroup C3 (animals killed at six months of age) in which the growth cartilage in the control and lengthened portions was practically identical (Figs. 5E and 5F).

Morphologically, the fracture gap filled with hematoma that was coagulated and organized peripherally ten days after distraction began (Fig. 6A). After several days, the hematoma tissue was replaced by fibrous reparative tissue (Fig. 6B) that underwent progressive ossification starting approximately on the 20th day after lengthening. The ossification was intramembranous (Fig. 6C), i.e., it did not pass through a cartilaginous phase. Normal enchondral ossification took place in the growth plate at the level of the calcified layer. Four months after the lengthening process was begun, practically all lengthened segments were completely ossified regardless of the distraction rate applied. Although differences were certainly slight, it should be mentioned that in Subgroup C3 (specimens lengthened at a slower velocity), a more advanced stage of reconstruction (higher trabecular density and more advanced neocorticalization) was observed as compared with Subgroup A3 and B3 specimens, which were subjected to higher distraction rates.

\section{DISCUSSION}

The majority of authors who have performed this bone lengthening technique, whether experimentally $^{6,8,10,12-14,16,18,21}$ or clinically ${ }^{1,2,5,8,9,17,19,20,25,31,32}$ share the opinion that physeal distraction is a method of proved efficacy for limb lengthening. The present 
authors' experience with this method proved effective in obtaining the planned lengthening. The results reported here are in agreement with the majority of authors who have published on this subject in that the basic mechanism involved in bone lengthening by physeal distraction results in an initial physeal fracture followed by progressive separation of the epiphysis and metaphysis. ${ }^{6,9,11,14,19-21,26,31,32}$ No signs indicative of stimulation of physeal plate activity ${ }^{4,22,23,28}$ or of physeal plastic deformation, as mentioned by some authors, were found. The widening of the physis observed on the lengthened side with respect to the control side in Subgroup A 1 is most likely due to the ischemia induced at the level of the metaphyseal slope of the growth cartilage after physeal fractures, as has been observed by others. ${ }^{27,29}$

With respect to fracture morphology, most authors likewise agree in their observations. A transverse physeal fracture has been observed, the line of which is localized between the hypertrophic and calcified layers. ${ }^{6,7,9,20,21,26,31,32}$ In the study reported here, fractures were observed in all cases regardless of the distraction rate employed, although the fracture line was only traced clearly in Subgroup A 1 and in Group D. In Subgroups B1 and. $\mathrm{C} 1$, a reparative process was already advanced by the time lengthening was concluded. The fracture lines observed in Subgroup Al and in Group D were also localized between the hypertrophic and calcified layers of the growth cartilage.

The most important question concerned the histologic evolution of the growth cartilage on the lengthened side. The possibility of damaging the growth cartilage through the application of traction forces on both sides of it was a question that had concerned Ring in $1958^{26}$ on finding premature fusions in the physis on the lengthened side, findings confirmed in later experimental studies. ${ }^{6,7,11,12,14}$ Monticelli and Spinelli, in their experimental studies, ${ }^{16,18,20}$ made abrupt physeal fractures (distraction epiphysiolysis) in lamb tibiae and observed cases in which the physis on the lengthened side showed distortions in the proliferative layer as well as an overall disorganization, while in other cases both growth plates (control and lengthened side) had close similarities. Such uncertainty as to the future effect this lengthening method may have upon the growth cartilage has limited its use to children near skeletal maturity. ${ }^{1,9,15,17,19,20,24,30}$

The present authors have observed how the morphology of the growth cartilage varied conspicuously in direct relation to the lengthening velocity employed. Thus, in those femora in which lengthening took place at a daily rate of $0.5 \mathrm{~mm}$, the growth cartilage remained virtually normal in all phases of study. However, in femora lengthened at a rate of $1 \mathrm{~mm} /$ day, and especially at $2 \mathrm{~mm} /$ day, obvious lesions were observed at 45 days and at four months postlengthening. These morphologic findings were later confirmed by the evolutionary study of the discrepancies obtained. The lower the distraction employed, the better was the long-term maintenance of the discrepancies. In consideration of these findings, it can be concluded that fundamental factors on which growth cartilage viability in physeal distraction depend are the abruptness with which fracture is produced and the distraction rate employed.

Finally, two important limitations must be mentioned that concern the possible clinical extrapolation based on the conclusions attained. First, the behavior of the physis of lambs after distraction may not be the same as that of humans. Second, it must be emphasized that the distracted physis in the present experiment was normal at the start, which is seldom the case in human practice.

On the basis of the results and in view of the clinical ramifications of this experimental study, it is concluded that physeal distraction at $0.5 \mathrm{~mm} /$ day permits lengthening and minimizes the significant risk of damage to the growth cartilage and of impairment of 
its function. This study supports physeal distraction as an option for lengthening at an early skeletal age. Furthermore, since growth cartilage can remain open, this method may be repeatable at later stages of growth.

\section{ACKNOWLEDGMENTS}

The authors wish to thank G. de Bastiani, M.D., R. Aldegheri, M.D., and L. RenziBrivio, M.D., for their contributions and continuous support of this project.

\section{REFERENCES}

1. Bensahel, H., Hugerin, P. H., and Biard, J. L.: L'Allongement transepiphysaire de tibia. A propos d'un cas. Rev. Chir. Orthop. 69:245, 1983.

2. Berchiche, R., and Wittek, F.: Allongement de sequelette jambier par epiphysiolyse-distraction. Traitement des inegalites des membres inferieurs. Acta Orthop. Belg. 49:321, 1983.

3. De Bastiani, G., Aldegheri, R., and Renzi-Brivio, L.: The treatment of fractures with a dynamic axial fixator. J. Bone Joint Surg. 66B:538, 1984.

4. De Bastiani, G., Aldegheri, R., Renzi-Brivio, L., and Trivella, G.: Limb lengthening by distraction of the epiphyseal plate. A comparison of two techniques in the rabbit. J. Bone Joint Surg. 68B:545, 1986.

5. Fischenko, P. J., Karimova, L. F., and Pilipenko, N. P.: Distraction epiphysiolysis in congenital shortening of lower extremities. Ortop. Travmatol. Protez. 37:44, 1976.

6. Fishbane, B. M., and Riley, L. H., Jr.: Continuous transphyseal traction. A simple method of bone lengthening. Johns Hopkins Med. J. 138:79, 1976.

7. Fishbane, B. M., and Riley, L. H., Jr.: Continuous transphyseal traction: Experimental observations. Clin. Orthop. 136:120, 1978.

8. Houghton, G. R., and Duriez, J.: Allongement tibial par elongation de cartilate de croissance tibial superieur. Etude experimentale chez le lapin. Rev. Chir. Orthop. 66:351, 1980.

9. Ilizarov, G. A., and Soybelman, L. M.: Some clinical and experimental data on the bloodless lengthening of lower limbs. Exp. Khir. Anes. 4:27, 1969.

10. llizarov, G. A., Soybelman, L. M., and Chirkova, A. M.: Some roentgenologic and morphological data on regeneration of bone tissue in experimental distraction epiphysiolysis. Ortop. Travmatol. Pro-tez. 31:26, 1970.

11. Jani, L.: Tierexperimentale studie uber tibiaverlangerung durch distraktionepiphyseolyse. Z. Orthop. 111:627, 1973.

12. Jani, L.: Die distraktionepiphyseolyse. Tierexperimentelle studie zum problem der beinverlangerung. Z. Orthop. 113:189, 1975.

13. Jones, C. B., Aichroth, P. M., and Dewar, D. E.: Gradual distraction of the epiphyseal growth plate: A human study of the forces generated and early effects on the growth plate. J. Bone Joint Surg. 67B:843, 1985.

14. Letts, R. M., and Meadows, L.: Epiphysiolysis as a method of limb lengthening. Clin. Orthop. 133:230, 1978.

15. Mezhenina, E. P., Roulla, E. A., Pechersky, E. G., Babich, V. D., Shadrina, E. L., and Mizhevich, T. V.: Methods of limb elongation with congenital inequality in children. J. Pediatr. Orthop. 4:201, 1984. 
16. Monticelli, G., and Spinelli, R.: Personal communication, 1979.

17. Monticelli, G., and Spinelli, R.: Allongement des membres par distraction epiphysaire. Rey. Chir. Orthop. 67:215, 1981.

18. Monticelli, G., and Spinelli, R.: Distraction epiphysiolysis as a method of limb lengthening: I. Experimental study. Clin. Orthop. 154:254, 1981.

19. Monticelli, G., and Spinelli, R.: Distraction epiphysiolysis as a method of limb lengthening: III. Clinical applications. Clin. Orthop. 154:274, 1981.

20. Monticelli, G., and Spinelli, R.: Limb lengthening by epiphyseal distraction. Int. Orthop. 5:85, 1981.

21. Monticelli, G., Spinelli, R., and Bonucci, E.: Distraction epiphysiolysis as a method of limb lengthening: II. Morphologic investigations. Clin. Orthop. 154:262, 1981.

22. Noble, J., Diamond, R., Stirratt, C. R., and Sledge, C. B.: Breaking force of the rabbit growth plate and its application to epiphyseal distraction. Acta Orthop. Scand. 53:13, 1982.

23. Noble, J., Sledge, C. B., Walker, P. S., Diamond, R., Stirratt, C. R., and Sosman, J. L.: Limb lengthening by epiphyseal distraction. J. Bone Joint Surg. 60B:139, 1978.

24. Ogden, J. A.: Skeletal Injury in the Child. Philadelphia, Lea \& Febiger, 1982, pp. 59-60.

25. Ricciardi, L.: Epifisiolisi distrazionale monocompartimentale. G. Ital. Ortop. Traumatol. 10:57, 1984.

26. Ring, P. A.: Experimental bone lengthening by epiphyseal distraction. Br. J. Surg. 49:169, 1958.

27. Salter, R. B., and Harris, W. R.: Injuries to the growth plate. In Rang, M. (ed.): The Growth Plate and its Disorders. Baltimore, Williams \& Wilkins, 1969, p. 133.

28. Sledge, C. B., and Noble, J.: Experimental limb lengthening by epiphyseal distraction. Clin. Orthop. 136:111, 1978.

29. Trueta, J., and Amato, V. P.: The vascular contribution to osteogenesis. III. Changes in the growth cartilage caused by experimentally induced ischemia. J. Bone Joint Surg. 42B:57 I, 1960.

30. Wevdenskogo, S. P.: Distraction epiphysiolysis of crural bones. Ortop. Travmatol Protez. 10:53, 1974.

31. Zavijalov, P. V., and Plaskin, J. T.: Elongation of crural bones in children using a method of distraction epiphysiolysis. Vestn. Khir. 103:67, 1967.

32. Zavijalov, P. V., Plaskin, J. T.: Distraction epiphysiolysis in lengthening of the lower extremity in children. Khirurgiia 44:121, 1968. 

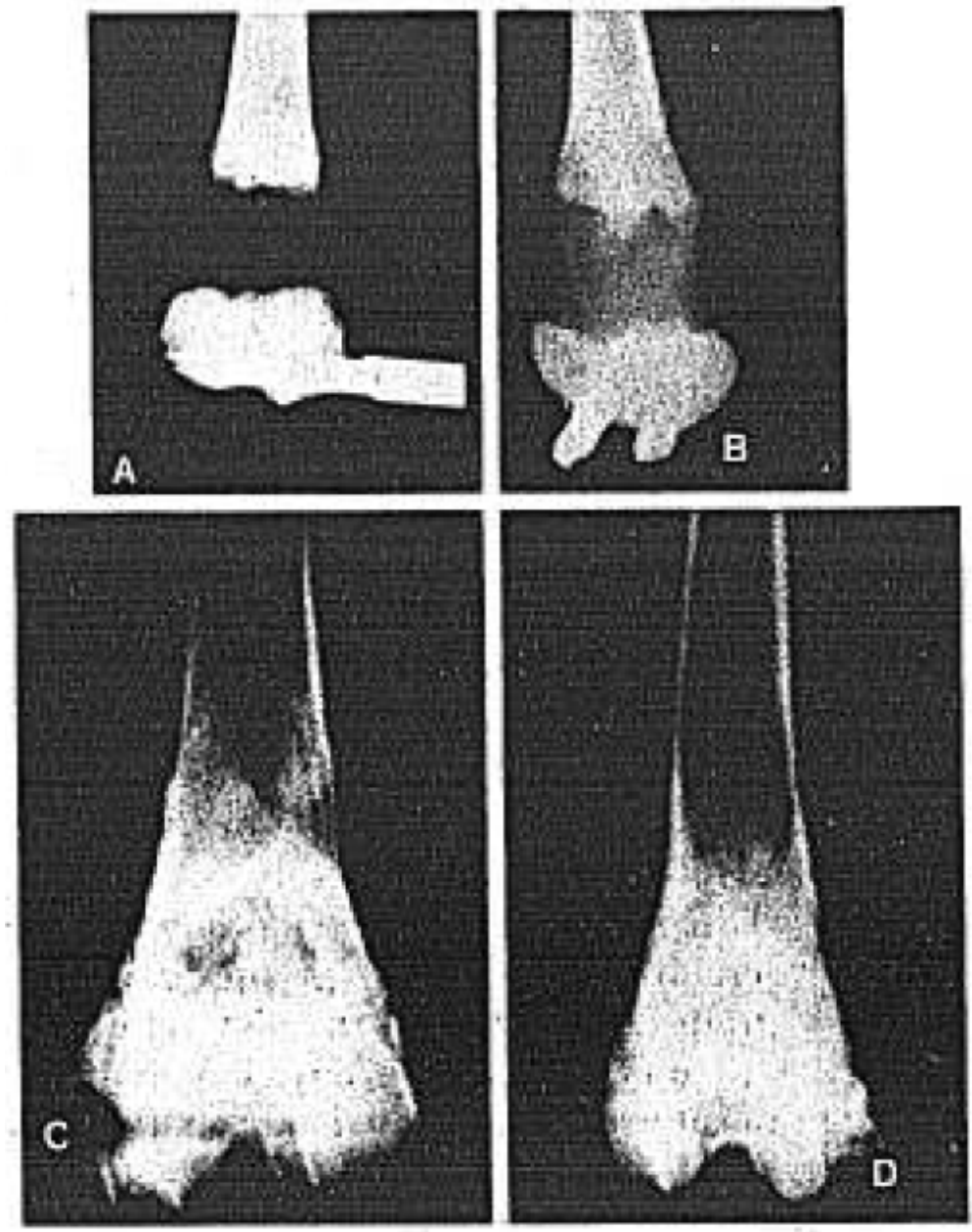

Figures 1A-1D. Roentgenologic study. (A) AP view of the distal femur just after distraction. (B) Lateral view. (C) 1.5 months after distraction. (D) Pour months after distraction was begun.

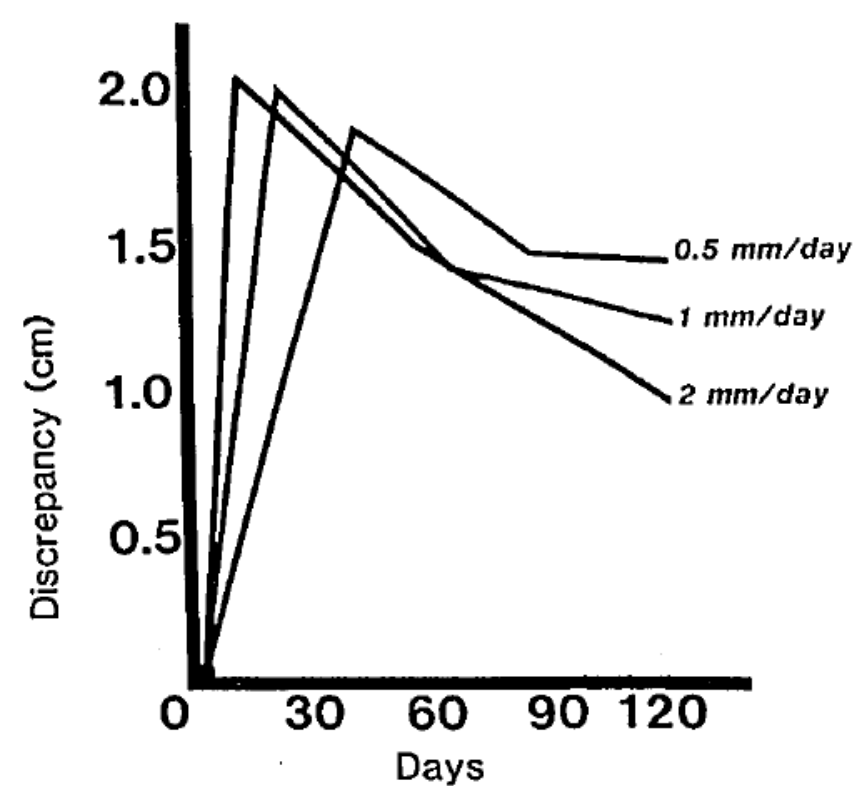

Figure 2. The average discrepancy between lengthened and contralateral limbs. 

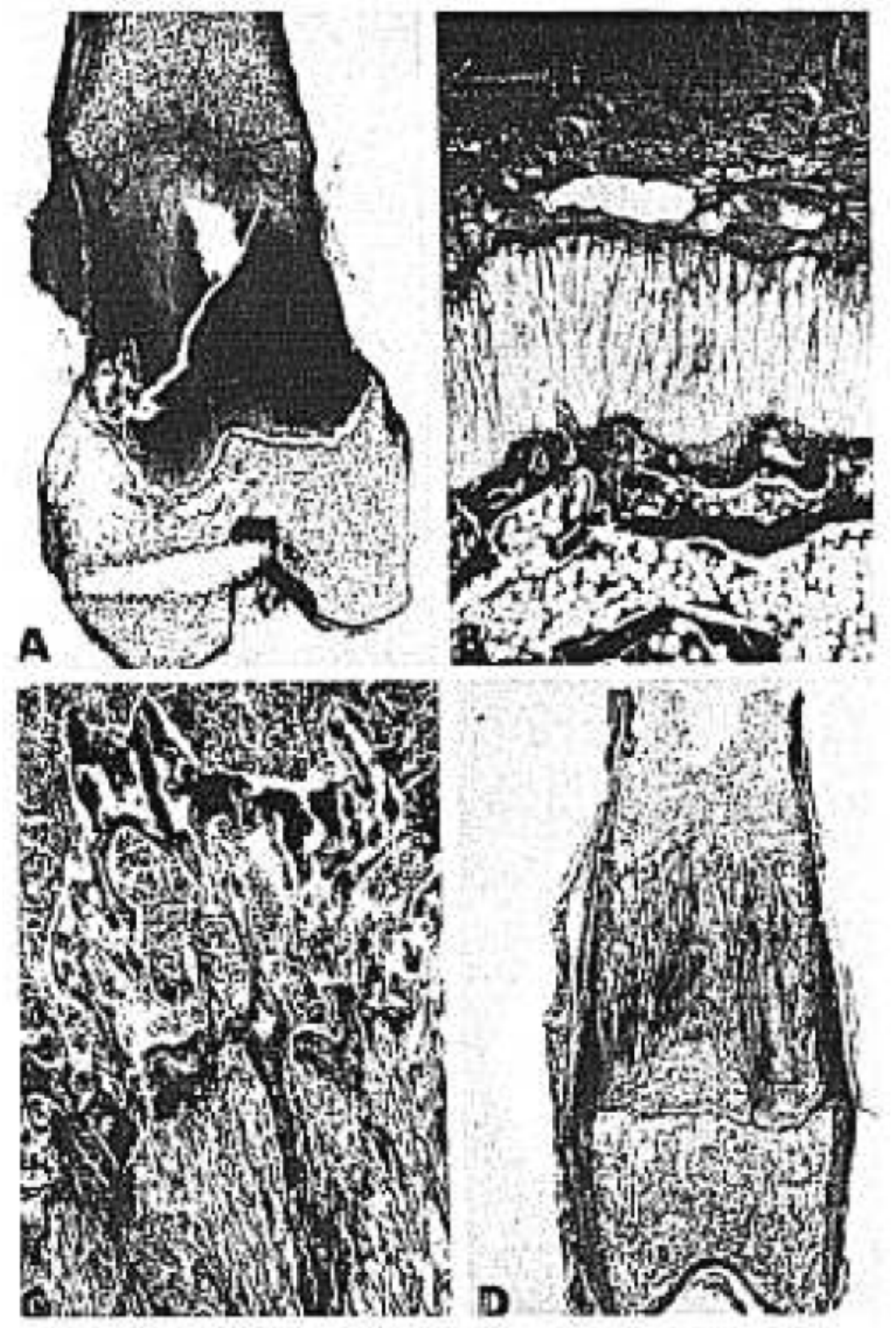

Figures 3A-3D. Histologic study. Immediate morphologic changes. (A) Macroscopy. Subgroup Al. Physeal fracture after distraction. (B) Subgroup Al. Epiphyseal slope of the fracture line. (Original magnification, x4.) (C) Subgroup A 1. Metaphyseal slope of the fracture line. (Original magnification, x10.) (D) Subgroup Cl. Physeal fracture after distraction. 


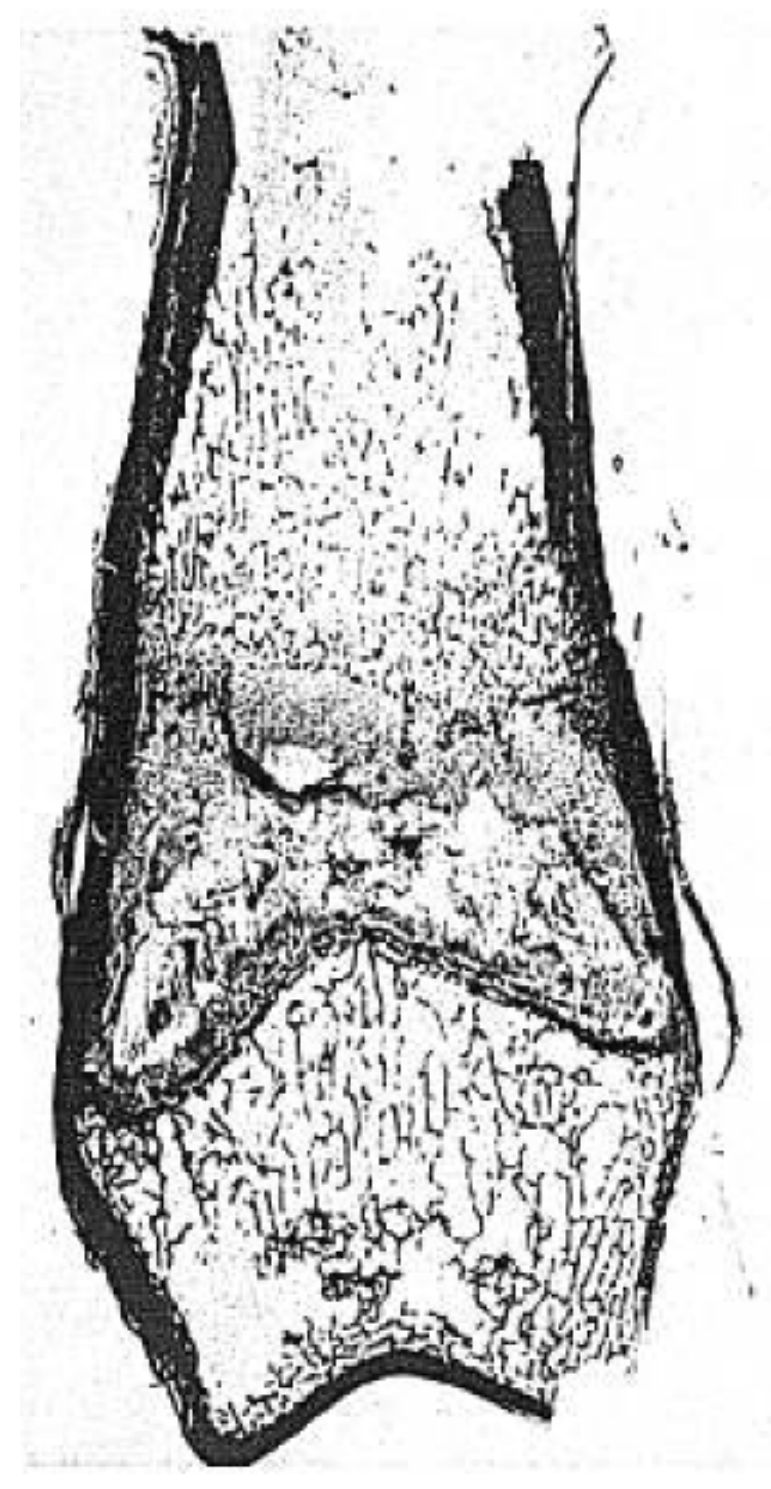

Figure 4. Histologic study of Group D. Note immediate morphologic changes. Under macroscopy, physeal fracture ten days after beginning of distraction was noted. 

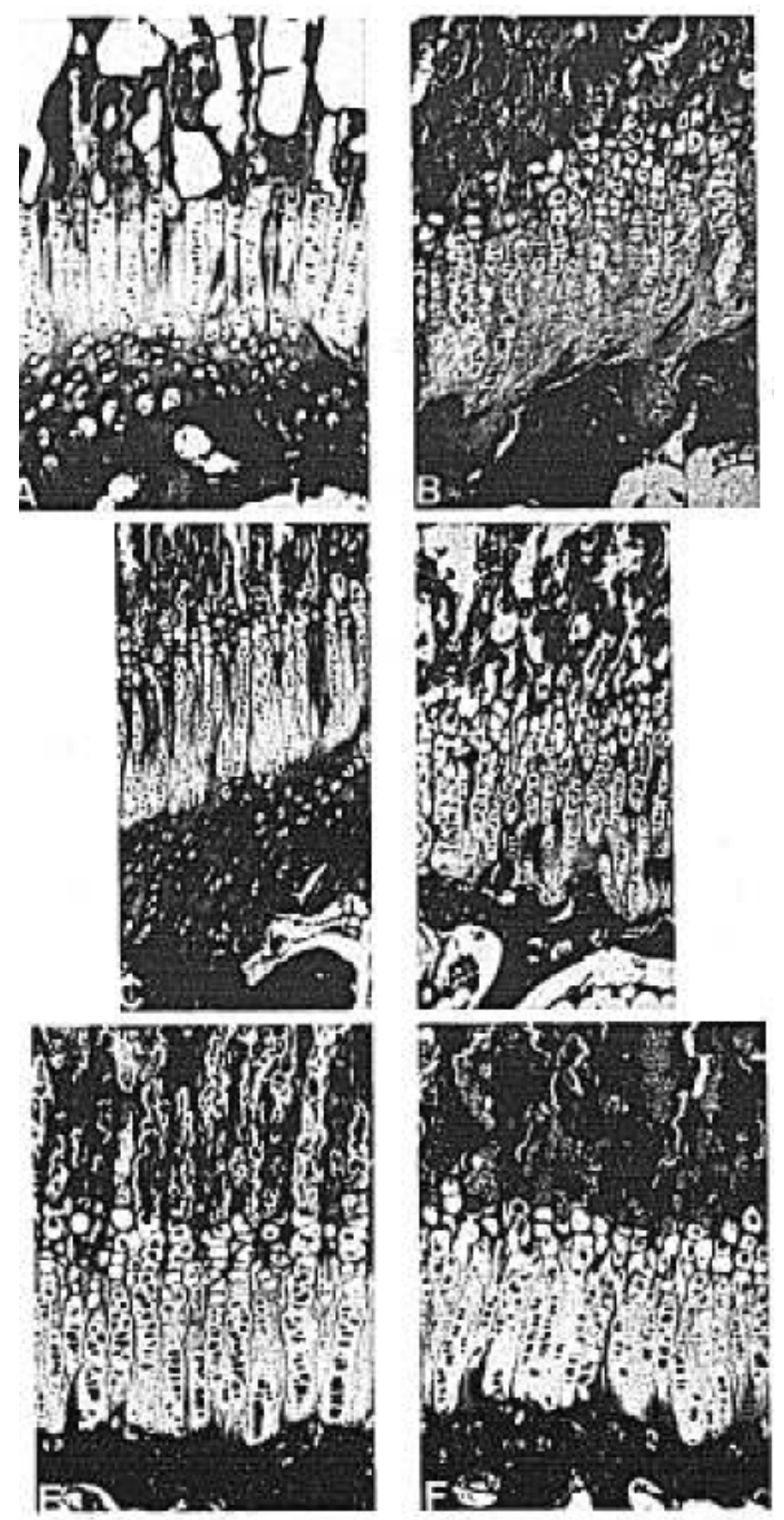

Figures 5A-5F. Histologic study of physeal changes at six months of age. Control, left; lengthened, right. (A and B) At $2 \mathrm{~mm} /$ day (A3). (C and D) At $1 \mathrm{~mm} / \mathrm{day}$ (B3). (E and F) At $0.5 \mathrm{~mm}$ /day (C3). (Stain, Masson's Trichromic; original magnification, $\mathrm{x} 10$.) 

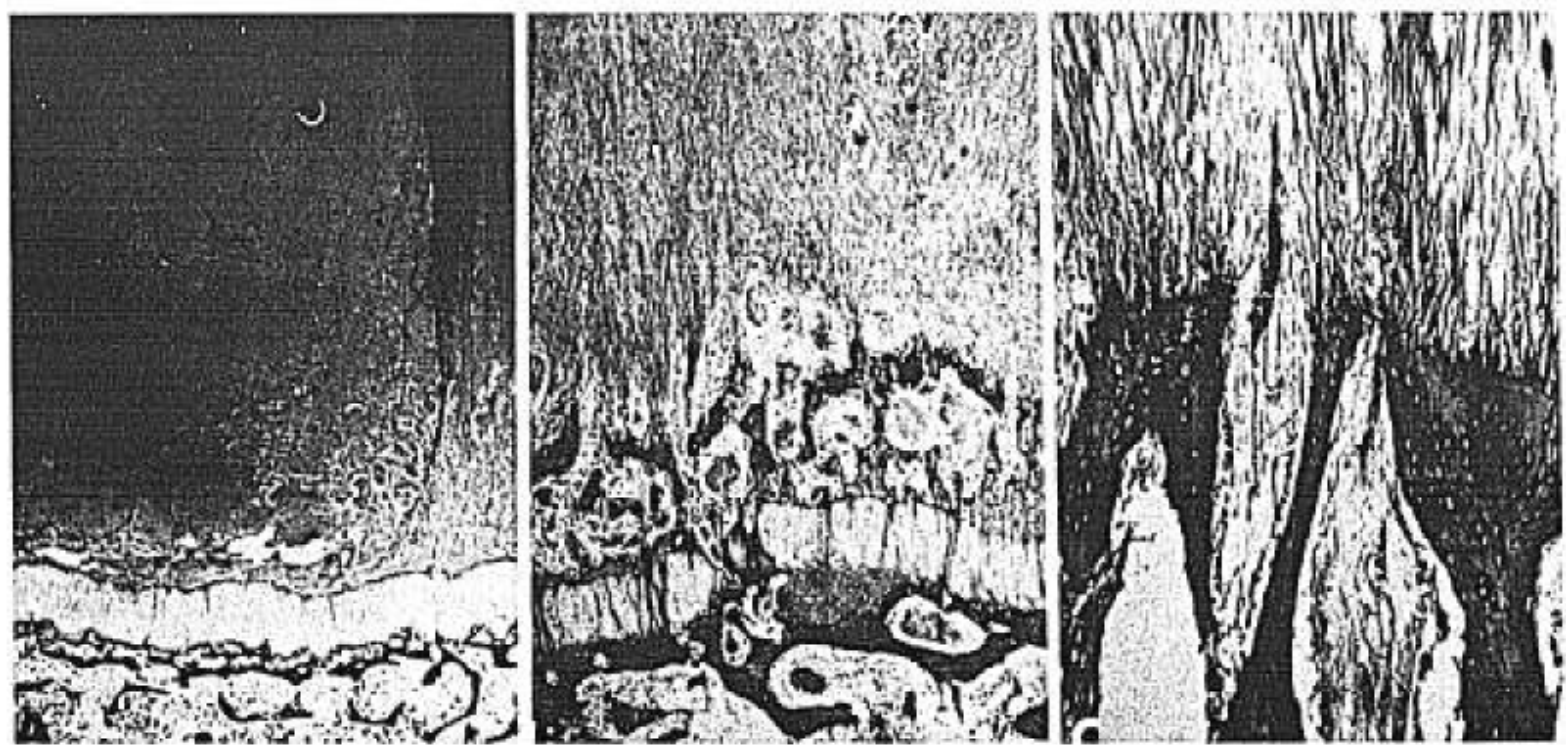

Figures 6A-6C. Histologic study. Morphology of the lengthened segment. (A) Fracturehematoma. (Stain, Masson's Trichromic; original magnification, x4.) (B) Fibrous granulation tissue. (Stain, Masson's Trichromic; original magnification, x4.) (C) Intramembranous ossification. (Stain, Masson's Trichromic; original magnification, $\mathrm{x} 10$. 